\title{
Pre-Service Educators’ Confidence and Efficacy in Dealing with Child and Adolescent Risk Behaviors in Diverse Classroom Settings
}

\author{
Tammy Jordan Wyatt \\ University of Texas at San Antonio
}

\begin{abstract}
Continuing behavioral research has documented the mounting prevalence of child and adolescent health risk behaviors. Fifty pre-service educators were assessed regarding their perception of critical factors that would influence their confidence, comfort, and efficacy levels in dealing with child and adolescent risk behaviors. Study results revealed that administrative support and legal concerns, personal experiences, educational training, the student's family, professional advice, and student support services influence preservice educators' reactions to student risk behaviors. Factors essential to enhancing pre-service educators' confidence, comfort, and efficacy levels include providing opportunities to gain skills in tackling risk behaviors; addressing legal issues, such as confidentiality, student rights, and district policies, within a teacher training program; offering professional advice regarding effective strategies for handling risk behaviors in the classroom and school settings; enlightening campus administrators of the importance of perceived teacher support; as well as informing counselors and other support personnel of their identified role as informational resources.
\end{abstract}

(c) 2006 Californian Journal of Health Promotion. All rights reserved.

Keywords: teacher training, pre-service teacher concerns, adolescent risk behaviors

\section{Introduction}

Over the past decade research has documented the growing prevalence of numerous child and adolescent health risk behaviors. These behaviors include sexual activity, alcohol and other substance abuse, tobacco use, unhealthy nutritional behaviors, and intentional injury (Centers for Disease Control and Prevention, 2004). A recent national study examining the sexual activity of adolescents aged 14 and younger, reports that approximately one in five adolescents has had sexual intercourse before his or her 15th birthday; approximately one in seven sexually experienced 14-year-old girls reports having been pregnant; and sexually experienced youth age 14 and younger are much more likely to smoke, use drugs and alcohol, and participate in delinquent activities than youth who have not had sex (Albert, Brown, and Flanigan, 2003).

In addition to increasing sexual behaviors, current data describe the rising trends in substance use among younger adolescents. A 2003 nationwide assessment of alcohol, tobacco, and other substance use among 8th graders, reports that just under $18 \%$ have smoked marijuana; nearly $16 \%$ have used inhalants; approximately $46 \%$ have drank alcohol; over $20 \%$ have been drunk; approximately $29 \%$ have smoked cigarettes; and $11 \%$ have used some form of smokeless tobacco (Johnston, O'Malley, Bachman and Schulenberg, 2003).

Unhealthy dietary behaviors among students are mounting as well. A significant number of high school students have used unsafe methods to lose or maintain weight. A nationwide survey found that during the 30 days preceding the survey, $13.5 \%$ of students used starvation strategies on one or more days; $5.4 \%$ vomited or used laxatives; and $9.2 \%$ took diet pills, powders, or liquids without the advice of a physician (Grunbaum et al., 2002).

Rates of intentional injuries, which include interpersonal (violence) and intrapersonal (suicide) forms of harm, are alarmingly high among school-aged youth. Firearms are the 
mechanism of injury in nearly $77 \%$ of homicides and $49 \%$ of suicides among children and adolescents aged 5-19 years (U. S. Department of Health and Human Services, 2000). For each reported death, there are an estimated 100 nonfatal intentional injuries each year. More than 400,000 youth aged 10-19 years reported being injured due to violent acts during the year 2000 (Centers for Disease Control and Prevention, 2001). Additional data note that three million thefts and violent crimes, including murder, sexual assault, physical assault, fighting with and without a weapon, robbery, and vandalism, occur on or near school campuses annually (Jones, 1998).

Even if they are not health education specialists, classroom teachers will encounter multiple health-related issues within the classroom and school settings. In United States elementary schools (grades K-6), health education is most commonly taught by regular classroom teachers. In middle schools (grades 6-8), health is often, but not always, taught by regular classroom teachers who have obtained certification in health, science, home economics, or physical education (Summerfield, 2001). Results of the School Health Policies and Programs Study (2000) indicate regular classroom teachers have a significant influence on the quantity and the quality of health education taught in schools (Kann, Brener, and Allensworth, 2001), particularly in schools that serve disadvantaged youth, whose health needs are substantial and often unmet. Additionally, elementary, middle, and high school teachers, irrelevant of primary subject taught, are often viewed as health resources by students who need information. The competencies in health education that are most often recommended for elementary and middle school teachers include use of the National Health Education Standards; demonstration of knowledge of various health issues such as injury prevention and safety, nutrition, alcohol, tobacco, and other substance use, sexuality, and nutrition; incorporation of health concepts into other areas of the curriculum; development of age-appropriate and culturally relevant health lessons; enhancement of health knowledge and development of health skills; and selection and use of valid sources of health information (Peterson, Cooper, and Laird, 2001).

Research, regarding diffusion of education innovations, reveals that teachers' concerns affect their adoption of curricular innovations (Steckler, Goodman, McLeroy, and Koch, 1992). Similarly, teacher efficacy has been examined in relation to teacher effectiveness and student outcomes within numerous studies. Teacher efficacy is strongly associated with student-efficacy (Anderson, Greene, and Loewen, 1988) and student achievement (Ashton and Webb, 1986; Ross, 1992). Moreover, efficacy beliefs influence teachers' persistence during difficult times and resilience in the face of setbacks. Teachers with a higher sense of efficacy exhibit greater enthusiasm for teaching (Allinder, 1994; Guskey, 1984; Hall, Burley, Villeme, and Brockmeier, 1992) and are more likely to stay in the teaching field (Burley, Hall, Villeme, and Brockmeier, 1991). Therefore, an essential research issue is how effective pre-service teacher development efforts are at increasing efficacy, confidence, willingness, and ability to teach, address, and manage child and adolescent risk behaviors in the diverse classroom and school settings of the 21st century. The purpose of this research study was to examine the levels of confidence, comfort and self-efficacy in relation to perceived educational preparedness in dealing with child and adolescent risk behaviors among pre-service educators specializing in grades 4-8. The research questions examined were:

1. In a population of pre-service educators, specializing in grades $4-8$, what are the factors that will be identified as key influencers to promoting confidence and efficacy in dealing with risk behaviors of children and adolescents?

2. What is the relationship among these influential factors in a population of preservice educators, specializing in grades 48 ?

There is no current literature using the specific qualitative methodology, Interactive Qualitative Analysis (IQA) (Northcutt \& McCoy, 2004), a systems approach to performing qualitative 
research, to examine pre-service educators' confidence and efficacy in dealing with child and adolescent risk behaviors. The IQA methodology allows the viewpoint of pre-service educators to be heard and key critical determinants to confidence and efficacy levels be established by the participants. This research encourages the future development and/or modification of teacher preparation programs to be contemporary and thus, take measures to enhance the comfort, confidence, and efficacy levels of pre-service educators in dealing with child and adolescent risk behaviors.

Through this study's analysis using the IQA methodology, critical factors and affinities that serve as key influences to pre-service educators' confidence, comfort, and efficacy in dealing with risk behaviors emerged and relationships between those factors were determined. Using IQA, emergent themes or affinities were named, relationships between affinities were represented, and the relative importance of each affinity within the overall process was quantified. The outcomes of each step of the IQA process build upon each other and therefore, the final product is a graphical as well as mathematical representation of the entire system of influences and outcomes. In this case, the system influence diagram (SID) displays key issues, which work in conjunction with one another to influence pre-service educators' confidence and efficacy in dealing with risk behaviors among students within future classrooms. See Figure 1 for a conceptual overview of the research study.

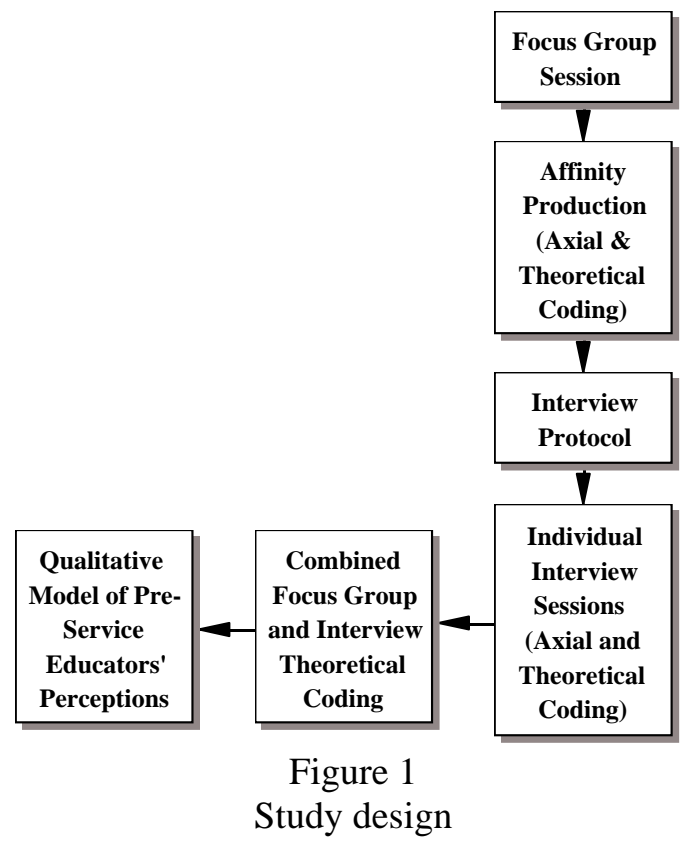

\section{Methods}

\section{Participants}

Using the university registrar's official student roster, solicitation e-mails via the university student e-mail service were sent to a total of 144 pre-service educators declaring a specialization in grades 4-8 teacher certification within the bilingual education, special education, and general education programs. In an attempt to recruit as many potential participants as possible, solicitation e-mails were also sent to a pool of 615 students within the interdisciplinary studies program whom were either degreeseeking only students or had not yet declared teacher certification and/or grade level specialization. Seventy-eight pre-service 
educators within the declared 4-8 certification pool responded and requested participation within the study for a response rate of 54 percent. Twenty pre-service educators from the degree-seeking only or undeclared pool responded and requested participation within the study for a response rate of three percent. To encourage high response rates and to recognize the value of the data provided, participants were offered a monetary incentive of $\$ 25$ to participate. From the pool of 98 participants a total of 50 were chosen using a stratified random sample (gender and ethnicity) to participate in the qualitative study $(\mathrm{N}=16$ within the focus group session; $\mathrm{N}=34$ within the individual interview sessions). The participants were between the ages of 18 and 57 years of age, with a mean age of 30.84 years (standard deviation of 10.67 years). The study sample was similar regarding gender and ethnic demographics to the official roster of pre-service educators declaring grade 4-8 teacher certification. The study and official roster demographics are listed respectively. Participants assessed were both male $(\mathrm{N}=10 ; 20 \% ; 19 \%)$ and female $(\mathrm{N}=40$; $80 \% ; 81 \%$ ) and from a variety of ethnic backgrounds: White, non-Hispanic $(\mathrm{N}=27 ; 54 \%$; 49\%); Latino ( $\mathrm{N}=17 ; 34 \%$; $41 \%)$; Black $(\mathrm{N}=5$; $10 \% ; 6 \%)$; and Other $(\mathrm{N}=1 ; 2 \% ; 3 \%)$. Eightyfour percent of the participants were classified as juniors, seniors, or post-baccalaureates.

\section{Focus Group}

The IQA research process began with a focus group session of 16 participants. The product of the focus group session was the development of affinities or themes, which serve as the foundation for the remaining study components. Per IQA protocol, participants were given blank note cards, identical markers, and a randomly chosen respondent number. Participants were instructed to reflect on their thoughts, beliefs, and experiences regarding dealing with adolescent risk-taking behaviors among their future students and then silently write their feelings, thoughts, ideas, beliefs, concerns, and experiences on the cards. After producing as many cards as possible, the group members taped their cards along a wall. The researcher and participants discussed the meaning of each card for clarity. The participants then silently arranged the cards into groups of meaning, an activity known as inductive coding. The group affinities (themes) were then named by the participants (axial coding) to reflect the perceived fundamental characteristics of each affinity. Next, participants were asked to define the causal relationship between each possible pair (presented as "A" and "B") of group affinities (theoretical coding) according to established rules: $A \rightarrow B, B \rightarrow A$, or no clear relationship. Participants recorded their individual responses in an Affinity Relationship Table (ART), a matrix containing all of the perceived relationships in the system. In examining pre-service educators' perceptions, this level of analysis begins to define the relative importance of each key influencer to confidence and self-efficacy in dealing with adolescent risk issues in the school setting.

\section{Interview}

The interview protocol was developed based upon the responses of the focus group session. The interview script was designed to guide the researcher in soliciting elaboration and expansion of the affinities produced from the focus group. Additionally, the interview script provided each respondent with the opportunity to establish a relationship with each affinity pair.

Interviews were conducted with 34 participants. Within the initial phase of the interview, participants were randomly assigned a respondent number for organizational purposes. Interview participants were asked to discuss their experiences with regard to each affinity and establish a relationship between each affinity pair (theoretical coding). For each interview session, the researcher identified various axial codes by noting key words or phrases that described the affinity and documented each within an Axial Code Table (ACT). Moreover, the researcher identified the series of relationships among each affinity pair as established by the interviewee $(\mathrm{A} \rightarrow \mathrm{B}, \mathrm{B} \rightarrow \mathrm{A}$, or $\mathrm{A}<>\mathrm{B}$ no clear relationship) and recorded each relationship within a Theoretical Code Table (TCT), referred to as an Affinity Relationship Table (ART) within the IQA focus group phase. 


\section{Statistical Analysis}

Following IQA protocol, data from each focus group participant's ART and each individual interview participant's TCT were analyzed and placed into an Interrelationship Diagram Matrix (IRD), a representation of the relative causal strength of each affinity (delta). The creation of the IRD began by calculating a cumulative frequency on the theoretical data allowing the researcher to establish a guideline for examining the strongest connections between the affinities. The conversion to graphic data began by calculating delta. All theoretical code tables were assembled and the frequency of an affinity being a cause ("out") versus being acted upon ("in") in each relationship was counted. The difference between the "out" sum and the "in" sum numerically indicated the relative causal strength of each affinity in the system, known as delta. Delta quantifies the causal "power" of each affinity. The value of delta is used as a marker for the relative position of an affinity within the graphical model of the system. Affinities with a positive delta are relative drivers or causes and those with negative deltas are relative outcomes or effects.

Using the Pareto Principle, the fewest number of relationships that represented the greatest amount of variation were included to create the model (Northcutt \& McCoy, 2004). The researcher was able to comprise a System Influence Diagram (SID), which served as a visual model of an entire system of influences and outcomes related to pre-service educators' confidence, comfort, and efficacy levels in dealing with child and adolescent risk behaviors in the classroom and school settings. Within the SID, recursions known as feedback loops developed. A feedback loop requires at least three affinities and has no beginning and no end. A feedback loop develops when affinities that appear to serve as causes influence successive affinities, which appear to serve as outcomes that in turn influence the previous causal affinities. As a visual representation of the system developed from the focus group and interview data, the SID may be considered as "a set of qualitative structural equations or a path diagram" in which recursion or feedback loops may be present (Northcutt \& McCoy, 2004).
Within the SID, primary drivers were placed to the left, primary outcomes to the right, and the secondary drivers and secondary outcomes in the middle. Each was named and arrows (links) were drawn to connect them according to causative relationships explicated in the IRD.

\section{Results}

\section{Affinities}

The results of the focus group session revealed seven affinities perceived to influence preservice educators' confidence, comfort, and efficacy levels in dealing with child and adolescent risk behaviors. These seven key influencers were: administrative and legal issues, educational training, the student's family, initial reactions, personal experiences, professional advice, and student support services. In-depth individual interview sessions were completed to provide elaboration, detail, and expansion in meaning of the seven affinities. From focus group and interview data the following affinity descriptions were generated.

The affinity administrative and legal issues was twofold in that it encompassed issues concerning the school administrators such as the principal and vice principal(s) as well as legal issues, for example, confidentiality, legal rights of the student, and school district policies. Participants expressed a strong desire for administrative support when dealing with all student issues, particularly issues that do not fall within the academic realm such as student risk behaviors. Being unaware of district policies and the campus administration's philosophy regarding the teacher's role in addressing risk behaviors were highlighted concerns. Many pre-service educators felt that it was the campus administrators' responsibility to inform teachers of the district and campus policies related to these issues rather than the teacher's responsibility to obtain that information.

Educational training referred to all classroom coursework as well as application, fieldwork experiences, including student teaching, at the participants' university. It was felt by many students that courses tended to be repetitive and in some cases the same textbooks were used for different required courses. Overall, most study 
participants felt satisfied in their ability to teach specific subject matter; however, concern was expressed regarding the participants' educational preparedness to deal with non-academic issues such as student risk behaviors. Study participants near the end of their degree program as well as those beginning the teacher certification program expressed the desire for a scenarios-based course, targeting appropriate ways for teachers to address risk behaviors within the classroom and school settings, to be included within the degree program.

The affinity family represented all family members or guardians that played an integral role in the academic and social life of the student. The primary concern of participants was the lack of parental involvement followed by effective methods of gaining parental involvement and establishing positive lines of communication related to risk behaviors with parents/guardians. Most study participants anticipated a lack of parental involvement at the upper elementary and middle school levels.

The affinity initial reactions were described as the teacher's emotional, verbal, non-verbal, and active responses to a particular student risk behavior. Potential emotional responses included sadness, anger, shock, confusion, worry, and concern as to how to best meet the student's needs. Several participants expressed concern over how to effectively address the student's needs while simultaneously maintaining a positive connection with the student.

Personal experiences added another dimension to pre-service teacher confidence and efficacy in the classroom. Participant experiences in classroom instruction unrelated to those mandated within the teacher certification program were varied. Participants with workrelated training in the field of education, such as instructional aids, substitute teachers, and afterschool mentors, expressed greater overall levels of confidence in dealing with student behaviors than participants with minimal or no work experiences. Similarly, participants whom engaged in or had experiences with risk behaviors as children and adolescents expressed a greater sense of confidence and efficacy in dealing with the specific behavior among their future students than those whom did not have such experiences. For example, participants who had familiarity with drug use in middle school felt better able to address student substance abuse concerns than participants who did not have similar past experiences.

Professional advice represented the counsel and guidance from individuals currently in the K-12 education field unrelated to the university setting. Professionals included teachers, principals, and counselors. While many participants described receiving advice from professionals on academic and pedagogical strategies, none reported receiving advice specific to student risk behaviors. Participants expressed a strong desire for guidance within this realm. One participant described the need for a teacher support group where all teachers could discuss effective ways to address student risk issues.

Lastly, the affinity student support services encompassed school personnel, such as the counselor, school psychologist, and nurse, whose responsibility is to meet the student's mental, emotional, psychological, and physical health needs. Support personnel were viewed as a teacher's primary resource for information regarding student health issues. Participants reported heavy workloads among support personnel, due to lack of adequate funding, and strong emphasis on standardized testing, as affecting quality student interactions, which in turn placed a greater responsibility on the classroom teacher to address student risk behavior issues.

\section{Systems Influence Diagram (SID)}

A cumulative frequency was calculated on the theoretical data from the focus group session and individual interview sessions to create the Composite IRD (see Table 1). Eight hundred forty three votes $(A \rightarrow B, B \rightarrow A, \quad A<>B)$ establishing perceived directional relationships were cast for a total of 42 established relationships between the seven affinities. IQA methodology follows Pareto's Principle, determining the fewest number of relationships that represent the greatest amount of variation. 
Within an IQA study, approximately $80 \%$ of the established relationship pairs should be used to create the model. Of the 42 established relationship pairs, 27 relationship pairs accounted for $82.4 \%$ of the total connections within the system and were used to create the model. The delta scores (see Table 1) were calculated and used to determine the causal "power" of each affinity. Based upon delta scores, the primary drivers (perceived causes) were administrative/legal issues and personal experiences. The secondary driver (perceived cause) was educational training. Professional advice, student's family, and student support services were secondary outcomes (perceived effects). Lastly, the primary outcome was initial reactions (perceived effect).

Table 1

Composite Interrelationship Diagram

\begin{tabular}{|c|c|c|c|c|c|c|c|c|c|c|}
\hline & $\mathbf{1}$ & $\mathbf{2}$ & $\mathbf{3}$ & $\mathbf{4}$ & $\mathbf{5}$ & $\mathbf{6}$ & $\mathbf{7}$ & $\mathbf{O U T}$ & $\mathbf{I N}$ & $\Delta$ \\
\hline 1 & & $\uparrow$ & $\uparrow$ & $\uparrow$ & & $\uparrow$ & $\uparrow$ & 5 & 0 & 5 \\
\hline 2 & $\leftarrow$ & & $\uparrow$ & $\uparrow$ & $\leftarrow$ & $\uparrow$ & $\uparrow$ & 4 & 2 & 2 \\
\hline 3 & $\leftarrow$ & $\leftarrow$ & & $\uparrow$ & $\leftarrow$ & $\leftarrow$ & $\uparrow$ & 2 & 4 & -2 \\
\hline 4 & $\leftarrow$ & $\leftarrow$ & $\leftarrow$ & & $\leftarrow$ & $\leftarrow$ & $\leftarrow$ & 0 & 6 & -6 \\
\hline 5 & & $\uparrow$ & $\uparrow$ & $\uparrow$ & & $\uparrow$ & $\uparrow$ & 5 & 0 & 5 \\
\hline 6 & $\leftarrow$ & $\leftarrow$ & $\uparrow$ & $\uparrow$ & $\leftarrow$ & & $\leftarrow$ & 2 & 4 & -2 \\
\hline 7 & $\leftarrow$ & $\leftarrow$ & $\leftarrow$ & $\uparrow$ & $\leftarrow$ & $\uparrow$ & & 2 & 4 & -2 \\
\hline
\end{tabular}

Affinity: 1. Administrative and Legal Issues; 2. Educational Training at UTSA; 3. Family of Student; 4. Initial Reactions; 5. Personal Experiences; 6. Professional Advice; 7. Student Support Services

The affinities were arranged in order with drivers placed to the left and outcomes to the right in a circular fashion. Arrows were drawn to represent relationships between affinity pairs. Redundant links, links between two affinities which if removed, a path from the driver to the outcome can still be achieved through an intermediary affinity, were removed according to the delta and model assignment beginning at the left and moving right. Redundant links are referred to as "paths of least resistance" (Northcutt \& McCoy, 2004). After all redundant links were removed systematically the final representation of the model was created. Figure 2 characterizes the simplest possible representation consistent with all the relationships contained within the IRD.

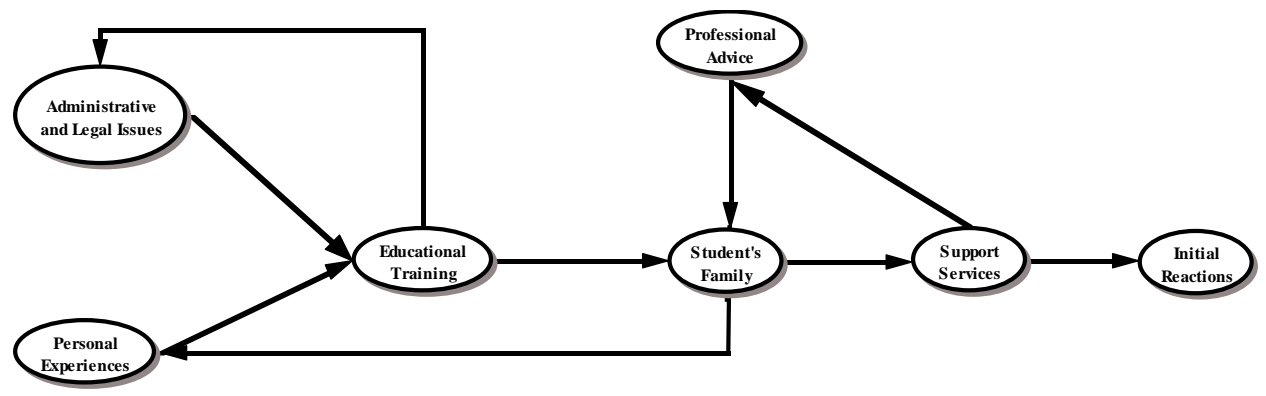

Figure 2

Model of Influencers to Pre-Service Educators' Confidence and Efficacy in Dealing with Child and Adolescent Risk Behaviors 


\section{Discussion}

The affinities administrative/legal issues and personal experiences, while not directly related to each other, were viewed as equivalent primary drivers within the model directly influencing pre-service educators' educational training. Statements of support included: "Whatever is going on in the state you work in is going to determine what kind of training the teachers need to have." "The training we get obviously needs to be in legal standards..." "I think the school [university] tries to teach you the right way to do it [address student needs] so you won’t get sued."

The educational philosophy and supportive nature of the campus administrator(s) was viewed as pivotal. For example, "We [teachers and administrators] have to be partners...I've seen schools where they [teachers and administrators] are not partners. I think that sometimes they [administrators] don't even know what is going on in certain classrooms. I want to have a partner for a principal." "They [administrators] are responsible for taking care of the teachers. When I come to them about a concern, I think that they [administrators] should be prepared to help guide me in how to fix that concern." "In the education system, teachers really don't have that much power. They [teachers] can have all the training in the world, and still their hands can be tied by the administration." "If I had the support of my administration then I would feel more confident in my job and be able to perform my job more efficiently and diligently.”

Likewise, personal experiences were viewed as dominating educational training. For example, “...if you've been through a particular situation and you're taught how to deal with it in school, you know it [how the school instructs you to handle the situation] is not going to work so you try to do something that worked for you in the past." Similarly, experiences were viewed as supplements to educational preparation. Statements to support this idea included: "Personal experiences affect it [training] because I apply a lot of what I have learned [in past experiences] to what I am learning [in my training]." "I use the experiences that I've had before to help make me a better teacher and to help add to my training." "Without personal experiences, there really is no training. Our stories influence what is trained in the schools [universities].”

Educational training was not only viewed by participants as being influenced by the administrative and legal issues, but participants also regard educational training as potentially affecting the administrative and legal concerns expressed by pre-service teachers. Remarks to support this included: "The classes [within teacher training programs] have to tailor to how administrations are set up and run as well as all the legal aspects of it [dealing with risk behaviors]. If you don't know all about that then you will probably be really confused when you get into teaching." "If I had the background and education in this [dealing with child and adolescent risk behaviors], I would be more confident in what I am doing so I would not be as concerned about legal issues.”

The educational preparation that one receives, colored by personal experiences, current educational laws, and perceptions of administrative support were expressed as directly influencing how a teacher interacts with parents and guardians in a particular risk situation. This was best seen in the following statements. "In the classes that I have taken, I have learned different ways of dealing with the family [regarding academic issues]... and what to expect from the family." "If I am better trained, the families [of my students] are going to realize it and trust me more as a teacher.”

The affinities student's family, personal experiences, and educational training formed a feedback loop (see Figure 3). The student's family was viewed as influencing the personal experiences of the participants, which in turn would have some bearing on previous educational training and future communication with a student's family. This is best expressed in the following statement. "I think that the training that I am getting as a student will influence the way that I interact with the parents. I think with my years as a teacher, it [how I respond to risk behaviors based upon prior educational training] 
might change as parents may influence me. Because I am fresh from school, school [training] influences me, but as years go on the parents may help me to become a better teacher."

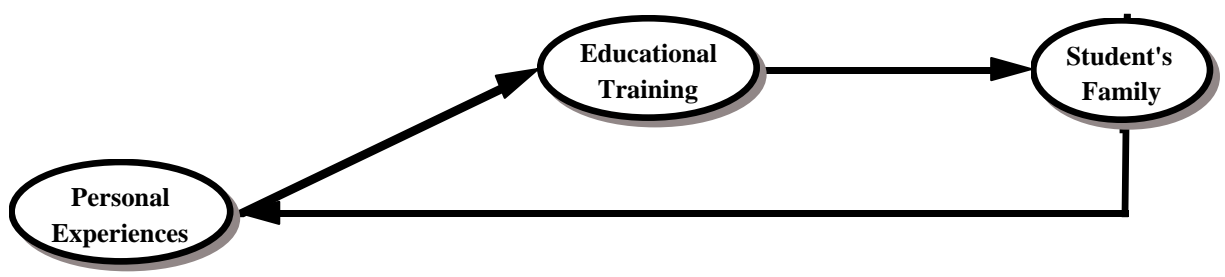

Figure 3

Feedback Loop: Student’s Family, Personal Experiences, and Educational Training

The secondary outcome affinities, student's family, support services, and professional advice were viewed as cyclical, meaning that each affinity is influenced by as well as influences the other two affinities, and formed a second feedback loop (see Figure 4). This was best represented in the following statements. "If I knew a student's family, it might change the way I thought about advice [and services] for that particular student." "Professionals can give the families advice regarding their student who needs help...therefore, the professionals [counselors, nurses, school psychologists, etc.] and teachers are able to help the family and give them the services they need." Student support services such as the counselor, nurse, and school psychologist were viewed by the majority of participants as providers of the professional advice given to teachers. Similarly, participants viewed other teachers as contributors of professional advice. For example, "Student support services are [examples of] professional advice [providers]." “They [student support services and teachers] work as a team...they feed off of each other." The knowledge and expertise of the aforementioned individuals was viewed as essential in addressing the risk-taking behaviors of students; however, the participants revealed extremely limited advice regarding effective strategies for addressing risk behaviors.

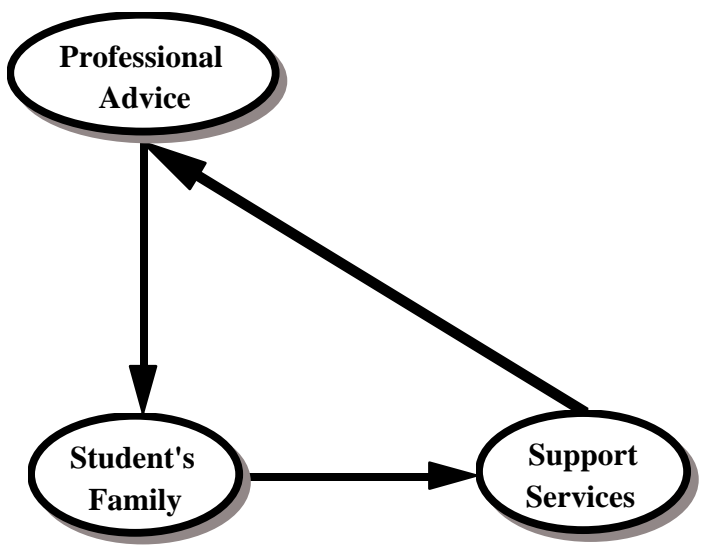

Figure 4

Feedback Loop: Student’s Family, Support Services, and Professional Advice 
Initial reactions, those emotional, verbal, nonverbal, and active responses to adolescent risk behavior situations, were directly influenced by support services. This was best represented in the following statements. "I will react with the counselor and the nurse upon how to act in a situation." "If something happens, the nurse will influence your reactions because the nurse is specialized." "The services available [to students] will affect how I react to them [students]." Reactions were also indirectly influenced by the preceding five affinities. Participants declared that they must take into account the level of administrative support on their campus, the district policies that are in place, prior personal experiences specific to the behavior at hand, any educational training that pertained to the behavior, the student's family, professional advice given that pertained to the behavior, and the availability of effective support service personnel prior to responding to a particular student risk behavior.

\section{Conclusions}

Diffusion of education innovations suggests that teachers' concerns affect their adoption of curricular innovations (Steckler et al., 1992). Similarly, teachers with a higher sense of selfefficacy exhibit greater enthusiasm for teaching (Allinder, 1994; Guskey, 1984; and Hall et al., 1992) and are more likely to stay in the teaching field (Burley et al., 1991). Therefore, examining pre-service educators' perceptions of their educational preparedness as well as other critical factors perceived to influence efficacy, confidence, willingness, and ability to manage child and adolescent risk behaviors in diverse classroom and school settings should be of interest to all in the field of education.

\section{Implications for Practice}

Legal concerns, such as confidentiality, student rights, and school district policies, served as primary influencers to confidence and efficacy levels in dealing with student risk behaviors. Educational preparation programs should include formal instruction that addresses current educational laws as well as methods for obtaining district policies related to such issues.
Administrative support was viewed as essential in dealing with risk behaviors as well. Participants reported administrative support as key to enhancing confidence, comfort, and efficacy. Thus, campus administrators should create a supportive environment for teachers, particularly when dealing with non-academic issues such as student risk behaviors.

Furthermore, professional advice pertaining to appropriate and effective strategies for dealing with risk behaviors was regarded as important to pre-service educators' confidence. However, this form of professional advice was reported as nonexistent. Additionally, student support personnel were considered the primary resource on a school campus for professional advice and information in dealing with risk behaviors. Hence, campus administrators should encourage mentorship, to include risk behavior information, of less experienced teachers by master teachers, counselors, nurses, and school psychologists.

Participants within this study reported educational training as strongly influencing levels of confidence and efficacy when dealing with risk behaviors. The pre-service educators participating in this study reported a lack of educational preparation in addressing child and adolescent risk behaviors in the classroom and school settings. Participants desired guidance in effective strategies for dealing with risk behaviors and a majority of participants specifically requested a scenarios-based course that would provide pre-service teachers with multiple opportunities to gain skills in addressing student health risk issues in appropriate, effective, and legal manners. When educational training in dealing with risk behavior is lacking, pre-service educators may rely on personal experiences, a key influencer to pre-service educator confidence, which may or may not be appropriate, effective, and/or abiding by state or district policy. Therefore, pre-service training programs should include formal training on child and adolescent risk behaviors as well as appropriate, effective, and legal strategies for dealing with such issues. Lastly, the student's family was revealed as a key influencer to preservice educators' levels of confidence and 
efficacy; therefore, educational preparation programs should include formal instruction concerning how to deal with parents in risk behavior as well as academic situations.

\section{Implications for Research}

While more than 80 percent of the participants within this study were upperclassmen, it is recommended that a study examining the perceptions of pre-service educators enrolled in their student teacher semester be conducted to better establish similarities in educational background. Additionally, it is recommended that a study examining the critical factors that influence confidence and efficacy in dealing with student risk behaviors be conducted among first-year teachers. Similarly, it is recommended that continued contextual study be applied to this area of research. The influential role of the administration and legal concerns of pre-service educators merits further investigation particularly for those researching within the field of educational leadership. The effective use of Interactive Qualitative Analysis (IQA) indicated a new direction for study that should continue in other educational research areas.

\section{Study Limitations}

The participants within this study were recruited from a mid-sized university in South Central Texas and therefore results may not be generalized to all pre-service educators or reflective of all educational preparation programs. Selection bias may exist in that students whom regularly check their university e-mail accounts may have been more likely to volunteer for the study than those whom do not regularly check their university e-mail. The low response rate within the degree-seeking only and undeclared pool of participants is a study limitation; however, by using a stratified random sample based upon gender and ethnicity representative of the population demographics the researcher minimizes this limitation. Lastly, qualitative research contains a variety of uncontrollable factors, which include the participants' interpretation of questions asked as well as the researcher's bias in coding of the data. However, the use of IQA theoretical coding techniques minimizes researcher bias.

\section{References}

Albert, B., Brown, S., \& Flanigan, C. (Eds.) (2003). 14 and Younger: The sexual behavior of young adolescents (summary). Washington, D.C: National Campaign to Prevent Teen Pregnancy.

Allinder, R. (1994). The relationship between efficacy and the instructional practices of special education teachers and consultants. Teacher Education and Special Education, 17, 86-95.

Anderson, R., Greene, M., and Loewen, P. (1988). Relationships among teachers' and students' thinking skills, sense of efficacy, and student achievement. Alberta Journal of Educational Research, 34(2), 148-165.

Ashton, P., and Webb, R. (1986). Making a difference: Teachers' sense of efficacy and student achievement. New York: Longman.

Burley, W., Hall, B., Villeme, M., and Brockmeier, L. (1991). A path analysis of the mediating role of efficacy in first-year teachers' experiences, reactions, and plans. Paper presented at the annual meeting of the American Educational Research Association, Chicago, IL.

Centers for Disease Control and Prevention (CDC). (2000). National Center for Health Statistics (NCHS), national health and nutrition examination survey (NHANES): NHANES 1999-2000. Prevalence of overweight among U.S. children and adolescents. Atlanta, GA: Author.

Centers for Disease Control and Prevention (CDC). (2001). Web-based injury statistics query and reporting system. National Center for Injury Prevention and Control. Retrieved May 5, 2004, from http://www.cdc.gov/ncipc/wisqars

Centers for Disease Control and Prevention (CDC). (2004). Surveillance summaries, May 21, 2004. MMWR, 53(No. SS-2).

Grunbaum, J., Kann, L., Kinchen, S., Williams, B., Ross, J., Lowry, R., and Kolbe, L. (2002). Youth risk behavior surveillance - United States, 2001. Journal of School Health, 72(8), 313-28. 
Guskey, T. (1984). Teacher efficacy, self-concept, and attitudes toward the implementation of instructional innovation. Teaching and Teacher Education, 81(1), 41-47.

Hall, B., Burley, W., Villeme, M., and Brockmeier, L. (1992). An attempt to explicate teacher efficacy beliefs among first year teachers. Paper presented at the annual meeting of the American Educational Research Association, San Francisco, CA.

Johnston, L. D., O'Malley, P. M., Bachman, J. G. \& Schulenberg, J. E. (December 19, 2003). Ecstasy use falls for second year in a row, overall teen drug use drops. University of Michigan News and Information Services: Ann Arbor, MI. Retrieved May 5, 2004, from http://www.monitoringthefuture.org

Jones, C. (1998). Preventing school violence: A review of the literature. Paper presented at the Annual Meeting of the Mid-South Educational Research Association, pp. 1-10. Retrieved September 19, 2000, from ERIC database (ED428445).

Kann, L., Brener, N., and Allensworth, D. (2001). Health education: Results from the school health policies and programs study (2000). Journal of School Health, 71(7), 266-278.

Northcutt, N., and McCoy, D. (2004). Interactive qualitative analysis: A systems approach for qualitative research. Thousand Oaks, CA: Sage Publications.

Peterson, F., Cooper, R., and Laird, J. (2001). Enhancing teacher health literacy in school health promotion: A vision for the new millennium. Journal of School Health, 71(4), 138-144.

Ross, J. (1992). Teacher efficacy and the effect of coaching on student achievement. Canadian Journal of Education, 17(1), 51-65.

Steckler, A., Goodman, R., McLeroy, K. R., and Koch, G. (1992). Measuring the diffusion of innovative health promotion programs. American Journal of Health Promotion, 6(3), 214-224.

Summerfield, L. (2001). Preparing classroom teachers for delivering health instruction. ERIC Clearinghouse on Teaching and Teacher Education Digest. Retrieved May 5, 2004, from http://www.ericsp.org

U. S. Department of Health and Human Services. (2000). Healthy People 2010 (2nd ed. Vol. 2). Washington, DC: U.S. Government Printing Office, 2000.

\author{
Author Information \\ Tammy Jordan Wyatt, Ph.D. \\ Assistant Professor \\ Department of Health and Kinesiology \\ University of Texas at San Antonio \\ 6900 North Loop 1604 West \\ San Antonio, TX 78249 \\ Ph.: 210-458-7285 \\ E-Mail: tammy.wyatt@utsa.edu
}

